\title{
Condicionantes da Saída da Pobreza com Microcrédito: O Caso dos Clientes do Crediamigo
}

\author{
- Ricardo Brito Soares* - Flávio Ataliba Barreto **

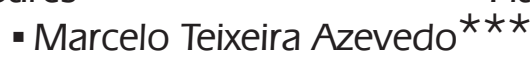

\begin{abstract}
Resumo
Esse artigo investiga a importância de alguns condicionantes facilitadores da saída da condição de pobreza dos clientes do Crediamigo/BNB, bem como a sua velocidade de ascensão neste programa de microcrédito produtivo, que é responsável por mais de $65 \%$ do mercado no Brasil. Para isto, utilizamos um modelo logístico de probabilidade de saída da pobreza, aplicado a clientes que ingressaram no programa com renda per capita familiar abaixo de linhas tradicionais delimitadoras deste estado de pobreza. Os resultados demonstram que os fatores facilitadores de ascensão dos mais pobres não se diferenciam dos fatores tradicionais para investidores do topo da pirâmide produtiva. Ou seja, uma probabilidade de sucesso maior ocorre para aqueles mais dotados de capital humano e de colaterais produtivos. Quanto às características dos empréstimos, verificamos que prazos menores de pagamentos, com valores medianos para empréstimos iniciais, facilitam o sucesso do nanoempresário. Estimamos também uma velocidade média de saída da pobreza entre $6 \%$ e $8 \%$ ao ano durante os primeiros cinco anos de programa. Este resultado sinaliza uma eficácia bastante alentadora do programa, que pode ser uma referência importante para políticas de desenvolvimento com estímulo mercadológico e com inclusão social.
\end{abstract}

\section{Palavras-Chave}

microcrédito, condições, saída da pobreza

\begin{abstract}
In this article we investigate some factors which contribute to alleviate the poverty conditions of the clients of the Crediamigo/BNB, as well as we estimate the velocity of ascension in this microcredit program, which is responsible for more than $65 \%$ of the market in Brazil. We use a logistic model for the probability of escaping poverty applied to the clients entering in the program with family per capita income below some traditional poverty lines. We found that the factors contributing to the rise of the poor are no different than the traditional factors for investors in the top of the production scale. That is, a higher probability of success occurs for those more endowed with human capital and productive collaterals. With respect to the features of the borrowings, we verified that short payment periods with median values for the initial credit facilitate the success of the micro entrepreneurs. We also estimated an average of escaping velocity of poverty around $6 \%$ and $8 \%$ a year during the first five years of program. This finding shows the high efficiency of the program which can be an important reference to development policies with focus both on market improvement and social inclusion.
\end{abstract}

\section{Keywords}

microcredit, conditions, escaping poverty

\section{JEL Classification}

$\mathrm{O} 10$

* Professor do Curso de Pós-Graduação em Economia da Universidade Federal do Ceará. E-mail: ricardosoares@caen.ufc.br.

** Professor do Curso de Pós-Graduação em Economia da Universidade Federal do Ceará. E-mail: ataliba@ufc.br.

$\star \star \star$ Mestre em Economia CAEN/UFC. Gerente de Microcrédito do Banco do Nordeste. E-mail: marceloat@ bnb.gov.br.

Endereço para contato: Ricardo Soares - CAEN - Av. da Universidade, $2700-2^{\circ}$ andar - Fortaleza - CE. CEP: 60020-181.

(Recebido em agosto de 2009. Aceito para publicação em novembro de 2010). 


\section{Introdução}

A dificuldade de acesso ao crédito por parte dos mais pobres tem sido apontada como um dos principais motivos que sustentam a armadilha da pobreza e a desigualdade de renda. A alta desigualdade de renda, por sua vez, pode ser um empecilho ao próprio crescimento econômico mais acelerado (PEROTTI, 1992; ALESINA; RODRIK, 1994; PERSON; TABELLINI, 1994). Este é o contexto no qual o microcrédito pode ganhar uma função social e econômica extra, que ultrapassa o simples interesse privado de sustentação e desenvolvimento das nano ou micro e pequenas empresas recorrentes. Acreditando nessa premissa, o Banco Mundial e vários países em desenvolvimento têm estimulado esta modalidade de crédito até mesmo como política de desenvolvimento.

Com esse apelo adicional de mecanismo de desenvolvimento, vários estudos sobre impacto na pobreza dos programas de microcrédito foram realizados, principalmente para alguns países da África, Ásia e América Latina. Uma síntese do impacto dos mais importantes programas desenvolvidos na década de 1990, nesses continentes, pode ser visto em Sebstad e Chen (1996), Schrieder e Sharma (1999) e Sharma e Buchenrieder (2002). Em termos gerais, os estudos apresentam resultados em várias direções sobre a contribuição desses programas no alívio da condição de pobreza. ${ }^{1}$

A possibilidade de evidências em diversas direções, quanto aos reais efeitos dos programas sobre a pobreza, pode estar relacionada não apenas a metodologias diferenciadas de avaliação de impacto, mas, sobretudo, a fatores específicos de cada programa de microcrédito e de seus clientes. Ou seja, uma possível falha de eficácia pode ser decorrente mais do tipo de programa, dos clientes e das condições de mercado do que do simples risco de concessão de crédito aos pobres em si. Neste sentido, é oportuno enfatizar que a literatura parece ter priorizado as análises de impacto em detrimento das análises de monitoramento ${ }^{2}$ dos clientes como que "apressando" um diagnóstico final sobre a validação do microcrédito como política de diminuição efetiva da pobreza. Khan (2009) enfatiza que essa tendência da literatura em se fazer avaliação de impacto do programa antes de avaliar o impacto no cliente surge também como uma demanda da própria indústria de microcrédito, geralmente mais interessada em ganhar escala do que necessariamente seguir compromissos de desenvolvimento macroeconômicos.

1 Ver, por exemplo, Hulme e Mosley (1996), Karlan (2001) e Morduch (1998) para estudos mais céticos quanto à contribuição líquida e extensiva dos programas de microcrédito no alívio da pobreza, e Copestake et al. (2005) e Khandker (2003) para evidências mais enfáticas de impactos.

2 Goldberg (2005) diferencia análises de impacto das de monitoramento, associando a primeira a análises comparativas de desempenho de grupos com e sem financiamento, enquanto o monitoramento envolve o acompanhamento apenas dos beneficiários do programa. 
Alguns autores, no entanto, atentam para a necessidade de se localizar, dentro do próprio programa e de seus contextos sociais, as virtudes e falhas da política de microfinanciamento. Goldberg (2005) cita o exemplo do Grameen Bank, que utiliza uma ferramenta de monitoramento dos clientes e dos mecanismos de crédito ao longo de suas permanências no programa, visando acompanhar a evolução de indicadores de saída da pobreza. Ou seja, uma vez que o pobre ganha acesso ao microcrédito, o que determina suas chances de saída da pobreza?

É de se imaginar que o próprio formato do programa, com respeito ao volume e tipo de crédito concedido, como também os prazos de pagamento dos clientes, podem influenciar diretamente nas estatísticas de sucesso/fracasso do mesmo. Ademais, características individuais dos tomadores como nível educacional e idade, os tipos de empreendimentos a serem financiados, assim como sua região de atuação podem também ser elementos decisivos nesse processo.

O programa Crediamigo do Banco do Nordeste do Brasil é o maior programa de microcrédito orientado do Brasil, sendo responsável por $60 \%$ no mercado nacional, e com projeções de expansão crescentes. Por ser um programa já consolidado e com uma política de acompanhamento "porta a porta" de seus clientes de baixa renda, ele oferece uma excelente oportunidade para uma investigação apurada dos condicionantes favorecedores (ou impeditivos) do êxito de saída da condição de pobreza. Além da atratividade natural advinda do próprio tamanho do programa, o Crediamigo é autofinanciado, não recebendo benefícios fiscais e com funding apenas de mercado. ${ }^{3}$ Todas suas despesas administrativas são cobertas pelas receitas geradas por meio dos juros cobrados dos clientes, o que garante que esse programa seja tratado internamente como uma unidade de negócios com uma gestão própria, que permite avaliações recorrentes de retornos e adimplências.

A investigação dos condicionantes de saída da pobreza para este programa é importante na medida em que pode auxiliar seus formuladores, demais instituições de financiamento e até mesmo o poder público no encaminhamento de ações que viabilizem o aumento da taxa de sucesso, e/ou que possam inibir ou buscar modificar atributos capazes de gerar resultados não satisfatórios. Nesse sentido, este artigo tem a preocupação central não de avaliar diretamente o impacto comparativo do programa Crediamigo na redução da pobreza, mas sim identificar, para aqueles que saíram da pobreza, quais foram os principais elementos responsáveis por influenciar de forma positiva essa trajetória. Medimos, no entanto, a eficácia interna do progra-

3 A captação de recursos para os empréstimos do Crediamigo atualmente origina-se exclusivamente de depósito interfinanceiro vinculado a operações de microfinanças (DIM), regulamentado pela Resolução BACEN 3422 e por contrato de empréstimo entre o BNB e o Banco Mundial. 
ma em reduzir a condição de pobreza de seus clientes não apenas pela capacidade de aumento de renda, mas também pelo tempo em que fazem.

O artigo está organizado da seguinte forma: além dessa introdução, a seção 2 apresenta as principais características do programa Crediamigo do Banco do Nordeste. A seção 3 mostra o modelo teórico pelo qual o microcrédito pode contribuir para o combate à pobreza. Na seção 4 , é discutida a base de dados e a metodologia utilizada. Na seção 5 , são apresentados os resultados empíricos e verificada a importância de cada condicionante a ser discutido, assim como a análise dos resultados. Por fim, a última seção é dedicada às considerações finais e discussões extensivas de políticas.

\section{Características Institucionais do Programa Crediamigo}

O programa de microcrédito do Banco do Nordeste do Brasil, conhecido como Crediamigo, foi lançado em 1998, após experiência piloto no ano anterior. Nos dias atuais, sua área de atuação concentra-se na região Nordeste e Norte dos Estados de Minas Gerais e Espírito Santo. ${ }^{4}$

Tomando por base o ano de 2006, 80\% de sua carteira de empréstimos foi realizada utilizando a metodologia do "aval solitário". Nessa forma de operação, o cliente, individualmente, não necessita dispor de garantias suficientes para receber o crédito, mas os recursos levantados são segurados por todos os membros do grupo ao qual o indivíduo pertence. Ou seja, se um tomador de microcrédito não pagar, o grupo terá que honrar o compromisso. Esse mecanismo acaba estimulando a solidariedade e o compromisso entre seus participantes. Nesse mesmo ano, o programa atendeu principalmente clientes com baixos níveis de escolaridade (68\% até oito anos de estudo) e de renda familiar $(60 \%$ até $\mathrm{R} \$ 1.000,00)$. O crédito concedido pelo programa é voltado para os pequenos empreendedores de baixa renda para aquisição de insumos, matérias-primas e/ou para pequenos investimentos.

Como a maioria das metodologias utilizadas para concessão de microcrédito, o Crediamigo também adota a figura do agente (ou assessor) de crédito, que gerencia uma carteira de clientes, normalmente delimitada por uma área geográfica. O programa tem como estratégia conceder empréstimos crescentes ao longo do tempo, condicionando ao pagamento do crédito anterior, com valores crescentes. Essa estratégia atua como incentivo ao pagamento dos empréstimos futuros, esperando que isso provoque um efeito positivo na redução de inadimplência. Por outro lado, o fato de o programa iniciar com valores mais baixos, permite selecionar os

4 Informações retiradas do Relatório Anual 2006. 
tomadores nos primeiros empréstimos com menores perdas para o grupo e para instituição credora. ${ }^{5}$

Os pagamentos normalmente são semanais, quinzenais ou mensais, dependendo do fluxo de receita dos clientes, e com prazos curtos de quatro meses, em geral, nos empréstimos para capital de giro. Isso pode trazer algumas vantagens para o banco como ajudar a selecionar os tomadores menos pontuais, além de permitir ao credor ter o retorno mais rápido do crédito. Assim como a maioria dos programas de microfinanças, o Crediamigo tem mais mulheres que homens como clientes ativos. A ideia por trás desse formato é a suspeição de que as mulheres são mais engajadas, pois apresentam menos risco de mobilidade e, por razões culturais, parecem ser mais sensíveis às punições sociais. Além disto, acredita-se que a mulher, de uma forma geral, tendo uma maior responsabilidade na educação e saúde dos filhos e por exercer atividades menos favorecidas que o homem, possa, através desse mecanismo, contribuir de forma mais decisiva na geração de renda na família, potencializando os resultados sociais daí advindos.

\section{Microcrédito e Combate à Pobreza}

A eficácia dos programas de microcrédito em reduzir a pobreza e ao mesmo tempo serem autossustentáveis depende da capacidade que estes têm de estimular e adequar o potencial empreendedor dos mais pobres aos mercados regionais. Néri (2001) explora múltiplas dimensões do crédito como alavanca de combate à pobreza citando efeitos desencadeadores como: i) melhora na utilização dos ativos da família, ii) aumento na capacidade de geração de renda e iii) melhora na habilidade dos pobres em lidar com as flutuações de renda.

5 Vale mencionar que, embora baixos, os empréstimos iniciais para cada cliente variam de acordo com a capacidade de pagamento projetada pelo banco a partir das informações iniciais dos mesmos. 


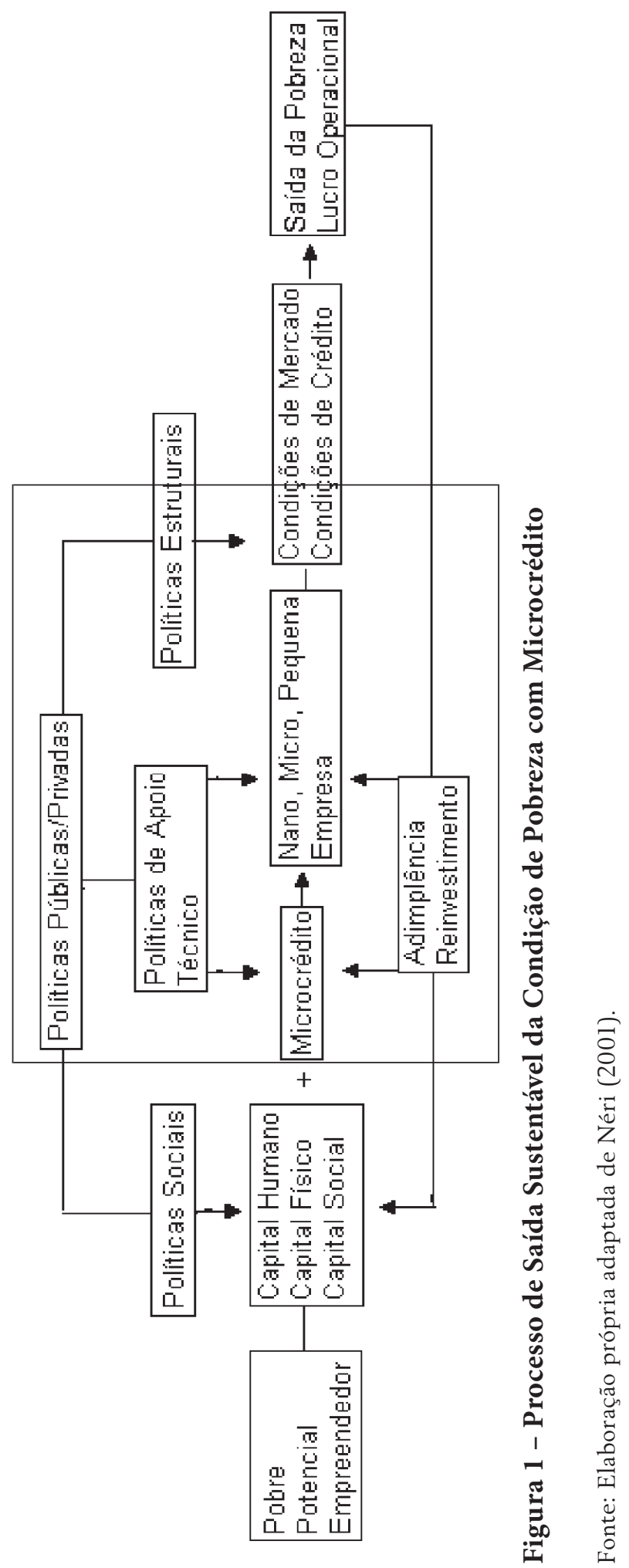


A Figura 1 ilustra não apenas o processo pelo qual o microcrédito pode contribuir para o alívio sustentável da condição de pobreza, mas também aponta o papel de possíveis políticas públicas neste processo. Neste esquema, o programa viabiliza a capacidade dos pobres de extrair retornos dos seus poucos ativos disponíveis (capital físico, capital humano e capital social) por meio de nanoempreendimentos. Essa premissa é sugestiva de que os pobres podem ser vistos como (nano) capitalistas potenciais e não apenas como pessoas segmentadas na sociedade (DE SOTO, 2000). É a continuidade deste processo, tendo como principal elemento propulsor a própria capacidade mercadológica desses empreendedores, que permite que a saída da condição de pobreza seja sustentável no médio e longo prazo.

No entanto, o sucesso do nanoempreendimento depende também das condições de crédito e de mercado aos quais ele é submetido e que, por sua vez, podem ser facilitadas por políticas públicas (políticas sociais, políticas de apoio técnico e políticas estruturais). Desta forma, temos um conjunto de fatores que podem influenciar na probabilidade de sucesso dos pobres em sair da condição de pobreza em que se encontravam ao ingressarem no programa de microcrédito.

\section{Base de Dados e Metodologia}

Sendo o segundo maior programa de microcrédito produtivo orientado da América Latina ${ }^{6}$ em número de clientes, o Crediamigo possui um conjunto de informações muito ampla de acompanhamento, que possibilita a investigação sobre os condicionantes que facilitam a ascensão dos mais pobres como nanoempreendedores. A base de dados utilizada neste trabalho inclui informações históricas sobre clientes ativos em 31/12/2006, e que tinham pelo menos dois fluxos de informações: o primeiro gerado na entrada no programa (condição inicial) e o segundo referente à sua posição final (último registro). Nesse critério, foram contabilizados inicialmente 196.692 clientes, que, após uma filtragem por falta de informações relevantes, foram reduzidos para $170.495 .^{7}$

6 O primeiro programa de microcrédito da América Latina é o mexicano COMPARTAMOS.

$7 \mathrm{Na}$ exclusão encontram-se todos os beneficiários do produto CREDIAMIGO COMUNIDADE, pois esta modalidade de empréstimo estava ainda no seu início e possui uma metodologia de acompanhamento diferenciada, e clientes sem informações para escolaridade, renda municipal e número de pessoas residentes. A falta de informações ocorreu principalmente no processo de operacionalização do programa (primeiro fluxo). Desta forma, a falta de informações para alguns clientes esteve mais relacionada à falta de prática dos gerentes do que ao tipo de cliente. Esta evidência ameniza a possibilidade de problema de seleção da amostra. Ademais, um teste de médias não apontou diferenças estatisticamente significantes entre os valores médios dos empréstimos para os clientes incluídos e excluídos da amostra, evidenciando uma capacidade de pagamento projetada pela instituição parecida para os mesmos. 
Desse grupo de clientes, focalizamos nossa atenção apenas naqueles que, ao entrarem no programa, possuíam renda familiar abaixo de um determinado nível que arbitrariamente definido por nós como linha de pobreza. No entanto, duas dificuldades apareceram com esse procedimento: a primeira está relacionada à própria definição do que é considerar um indivíduo como sendo pobre, ou seja, qual a linha de pobreza que deveria ser adotada. A segunda refere-se à falta de informação direta sobre a renda familiar do indivíduo.

A determinação da linha da pobreza é importante, pois nossa análise será focada naqueles indivíduos que conseguiram cruzar esta linha após entrarem no programa. Como as discussões a respeito de suas possíveis mensurações e adequações são extensas (WORLD BANK, 2007), decidimos por três linhas de renda utilizadas no Brasil. A primeira, de meio salário mínimo (LP 1/2 SM) é utilizada como referência para alguns programas governamentais. A segunda (LP 1/2 SM-R), além de usar como referência o salário mínimo, leva em consideração os padrões de vida diferenciados entre os Estados. Por fim, uma terceira linha (LP PV-R) também faz diferenciação de padrões de vida entre regiões, mas ela é condicionada pelas necessidades nutricionais. ${ }^{8}$ A Tabela 1 mostra o valor destas linhas de pobreza em outubro de $2006^{9}$ para cada Estado participante do programa Crediamigo.

\section{Tabela 1 - Linhas de Pobreza - Outubro/2006}

\begin{tabular}{lccc}
\hline \multirow{2}{*}{ Estado } & \multicolumn{3}{c}{ Linhas da Pobreza (R\$) } \\
\cline { 2 - 4 } & LP $1 / 2$ SM & LP $1 / 2$ SM-R & LP PV-R \\
\hline Alagoas & 175,00 & 165,60 & 115,88 \\
Bahia & 175,00 & 169,72 & 115,88 \\
Ceará & 175,00 & 159,43 & 115,88 \\
Distrito Federal & 175,00 & 165,60 & 117,38 \\
Espírito Santo & 175,00 & 131,66 & 122,13 \\
Maranhão & 175,00 & 165,60 & 115,88 \\
Minas Gerais & 175,00 & 149,15 & 122,13 \\
Paraíba & 175,00 & 167,66 & 115,88 \\
Pernambuco & 175,00 & 178,97 & 115,88 \\
Piauí & 175,00 & 164,57 & 115,88 \\
Rio Grande do Norte & 175,00 & 166,63 & 115,88 \\
Sergipe & 175,00 & 168,69 & 115,88 \\
\hline
\end{tabular}

Fonte: Manso et al. (2008).

8 Para mais informações, ver Manso et al. (2008).

9 Todos os valores monetários das informações de empréstimo para primeiro e segundo fluxos foram deflacionados para outubro de 2006. 
Na falta de informação direta sobre renda familiar, adotamos uma variável proxy determinada pela adição de duas contas do cliente: lucro operacional e outras receitas familiares. O lucro operacional refere-se exatamente ao valor de retirada do negócio que, somado a outras receitas familiares, contabilizam a disponibilidade de recursos da família. Dado que essas informações são coletadas por Assessores de Crédito treinados pelo BNB com um viés conservador, ${ }^{10}$ acreditamos que elas determinam uma aproximação bastante razoável da renda dos clientes que tomam esses tipos de empréstimos.

É importante destacar que a soma destas duas rubricas (lucro operacional e outras receitas familiares) foi realizada para determinar a renda familiar do cliente ao entrar no programa apenas, e assim identificar este como estando ou não na situação de pobreza. No cálculo da renda familiar atual do cliente, levamos em consideração o que se adicionou a esta renda familiar inicial, proveniente exclusivamente do negócio financiado. Ou seja, o valor da renda familiar atual é dado pelo valor da renda inicial mais a variação no lucro operacional após a entrada no programa como mostrado a seguir:

$$
\begin{aligned}
& \text { Renda Familiar }_{t 0}=\text { Lucro operacional }_{t 0}+\text { Outras receitas familiares }_{t 0} \\
& \text { Renda Familar }_{t 1}=\text { Renda Familiar }_{t 0}+\Delta \text { Lucro operacional }_{t 1} \\
& \text { e } \Delta \text { Lucro operacional }_{t 1}=\text { Lucro operacional } \\
& t 1
\end{aligned}
$$

De posse das variáveis de renda familiar para os dois períodos, o procedimento utilizado foi dividir a renda familiar pelo número de pessoas da família, de modo a se obter o valor da renda per capita familiar do cliente, ${ }^{11}$ o que permitiu identificar sua condição de pobreza para os dois períodos. ${ }^{12}$

A Tabela 2, a seguir, nos mostra a matriz de transição dos clientes entre os dois fluxos de registros (entrada no programa e condição atual).

10 O viés conservador ocorre, pois a disponibilidade de renda da família é um fator determinante no montante de crédito concedido pelo banco.

11 Devido ao excessivo número de informações incompletas no primeiro cadastro da operação para a variável indicadora do número de familiares residentes (22\% de perda), utilizamos apenas a informação do último fluxo do cliente. Vale ressaltar que, entre os clientes que proveram informações para os dois fluxos, mais de $95 \%$ não modificaram o número de familiares declarados entre os dois fluxos, o que favorece este procedimento vis-à-vis uma perda considerável de graus de liberdade.

12 É importante mencionar que, para o segundo período, a renda familiar, como definida, fornece uma condição de pobreza potencial, pois variações em outras receitas de familiares podem também contribuir para o aumento (ou diminuição) da renda da família. No entanto, variações no complemento de renda da família não estão diretamente ligados ao desempenho do negócio após a entrada no programa e, por isso, foram excluídas do indicador de desempenho (saída da pobreza). 
Tabela 2 - Matriz de Transição da Situação de Pobreza - Clientes Crediamigo

\begin{tabular}{|c|c|c|c|c|c|c|c|}
\hline & & \multicolumn{6}{|c|}{ Condição Atual } \\
\hline & & \multicolumn{2}{|c|}{ LP PV-R } & \multicolumn{2}{|c|}{ LP $1 / 2$ SM-R } & \multicolumn{2}{|c|}{ LP $1 / 2 S M$} \\
\hline & & $\begin{array}{l}\text { Não } \\
\text { Pobre }\end{array}$ & Pobre & $\begin{array}{l}\text { Não } \\
\text { Pobre }\end{array}$ & Pobre & $\begin{array}{l}\text { Não } \\
\text { Pobre }\end{array}$ & Pobre \\
\hline \multirow{2}{*}{$\begin{array}{l}\text { Condição } \\
\text { de Entrada }\end{array}$} & Não Pobre & $\begin{array}{l}143.772 \\
(98,4 \%) \\
\end{array}$ & $\begin{array}{l}2.217 \\
(1,6 \%)\end{array}$ & $\begin{array}{c}116.933 \\
(97 \%)\end{array}$ & $\begin{array}{c}3.609 \\
(3 \%) \\
\end{array}$ & $\begin{array}{l}111.385 \\
(96,7 \%) \\
\end{array}$ & $\begin{array}{l}3.779 \\
(3,3 \%) \\
\end{array}$ \\
\hline & Pobre & $\begin{array}{c}14.299 \\
(58,3 \%)\end{array}$ & $\begin{array}{c}10.207 \\
(41,7 \%)\end{array}$ & $\begin{array}{c}25.064 \\
(50 \%)\end{array}$ & $\begin{array}{c}24.889 \\
(50 \%)\end{array}$ & $\begin{array}{c}26.802 \\
(48,4 \%)\end{array}$ & $\begin{array}{l}28.529 \\
(51,6 \%)\end{array}$ \\
\hline
\end{tabular}

Podemos constatar, de início, um índice de sucesso em sair da condição de pobreza bastante alentador para o programa Crediamigo (58,3\% para LP PV-R, 50\% para LP $1 / 2$ SM-R e $48,4 \%$ para LP $1 / 2$ SM). Observamos também que a proporção de clientes em situação reversa, ou seja, reduções de renda ao nível de pobreza, foi muito pequena, sugerindo uma alta eficácia líquida e interna dos clientes em sair da condição de pobreza inicial na qual se encontravam.

Neste trabalho, investigamos exatamente os fatores que contribuíram para esta probabilidade de sucesso. Para isto, estimamos um modelo Logit multivariado, para um conjunto de variáveis que incluem: i) o tempo de programa, ii) características individuais e familiares (idade, nível educacional, gênero e tipo de domicílio), iii) características do negócio (estrutura, tempo de atividade, setor, tipo de controle administrativo e prazo de venda), iv) características do empréstimo (valor, prazo e participação no empréstimo do grupo solidário) e v) aspectos regionais (efeito fixo dos Estados e renda per capita municipal). O Quadro 1, a seguir, apresenta um maior detalhamento conceitual das variáveis utilizadas. ${ }^{13}$

Cabe destacar que a variável categórica tempo de programa procura evidenciar a dinâmica dos clientes pobres em sair desta condição econômica. Esta variável também capta, em parte, a eficácia do próprio programa de acompanhamento do Crediamigo, considerando o efeito do apoio técnico personalizado dos agentes de crédito sobre os clientes mais vulneráveis.

13 A média das variáveis usadas no modelo encontra-se na Tabela Al do Apêndice. 


\begin{tabular}{|l|l|}
\hline CATEGORIA & \multicolumn{1}{c|}{ TIPO/CARACTERÍSTICAS } \\
\hline Tempo de Programa & $\begin{array}{l}\text { Tempo de Programa - Variável categórica. Faixas categóricas de seis meses (acumulados) } \\
\text { de participação no programa contabilizadas a partir da data de entrada (primeiro fluxo). }\end{array}$ \\
\hline Indivíduo e Família & $\begin{array}{l}\text { Idade - Idade em anos ao entrar no programa. } \\
\text { Nível Educacional - Variável categórica. Condição educacional ao entrar no programa: } \\
\text { analfabeto, primeiro grau incompleto, primeiro grau completo, segundo grau incompleto, } \\
\text { segundo grau completo, superior incompleto ou superior completo. } \\
\text { Gênero - Variável binária: 1 = Homem, 0 = Mulher. } \\
\text { Tipo de Domicílio - Variável categórica. Própria, alugada, emprestada, de familiares ou } \\
\text { não informada. }\end{array}$ \\
\hline Empresa & $\begin{array}{l}\text { Estrutura Física do Negócio - Variável binária: 1 = Ambulante, 0 = Fixo. } \\
\text { Tempo de Atividade - Quanto tempo o cliente tem de experiência na atividade (informada } \\
\text { pelo mesmo - em anos). } \\
\text { Setor de Atividade - Variável categórica. Comércio, indústria ou serviço. } \\
\text { Tipo de Controles Administrativos - Variável categórica construída de acordo com a } \\
\text { classificação do Assessor de Crédito em visita ao negócio: bom, satisfatório, precário e } \\
\text { inexistente. } \\
\text { Prazo de Venda do Cliente - Variável categórica. O cliente pode responder que vende } \\
\text { somente à vista, ou com prazos variando de 1 a } 3 \text { meses. }\end{array}$ \\
\hline Empréstimo & $\begin{array}{l}\text { Valor do Empréstimo ou Financiamento - Variável Categórica. Faixa de valor individual } \\
\text { que o cliente recebeu de crédito quando iniciou no programa. } \\
\text { Prazo do empréstimo ou financiamento - Variável categórica. Prazo em meses do } \\
\text { empréstimo. } \\
\text { Participação no grupo solidário - Participação porcentual do empréstimo individual no } \\
\text { montante do grupo solidário. }\end{array}$ \\
\hline Regional & $\begin{array}{l}\text { Estado - Variável categórica. Efeito Fixo do Estado da Federação em que o cliente está } \\
\text { localizado } \\
\text { Renda per capita municipal - Renda per capita do município onde está localizada a } \\
\text { atividade produtiva do cliente (2000). }\end{array}$ \\
\hline
\end{tabular}

\section{Quadro 1 - Variáveis Explicativas}

Fonte: Ipeadata.

Para extrair efeitos quantitativos de fácil interpretação do modelo Logit, seguimos Chowdhury et al. (2005) e calculamos efeitos marginais para valores médios das variáveis explicativas. ${ }^{14}$ Desta forma, podemos dizer que temos efeitos marginais de saída da pobreza para indivíduos médios. Nossa variável dependente, portanto, é uma variável dicotômica igual a 1 se o indivíduo conseguiu sair da condição de pobreza, e 0 , caso contrário. Deve-se ainda relatar que todas as variáveis explicativas incluídas são referenciadas à época da entrada do indivíduo no programa (primeiro fluxo), para evitar problemas de endogeneidade.

14 Os efeitos marginais, neste caso, são calculados como variações discretas nas probabilidades esperadas. Ver mais em Long (1997). 


\section{Resultados}

A Tabela A2 (Apêndice) mostra os coeficientes e efeitos marginais dos modelos Logit estimados. Pode-se verificar que não há grandes variações qualitativas nos resultados das variáveis explicativas para as três linhas de pobreza consideradas, o que sugere uma robustez para os resultados apresentados a seguir. Por simplicidade, nossa análise será centrada em algumas variáveis tradicionais de retorno, ou que evidenciem dotações (colaterais) diferenciadas mesmo entre os mais pobres. Desta forma, pode-se avaliar se o padrão de crescimento dos nanoempreendimentos se assemelha a de qualquer outra empresa. Evidentemente, outros resultados ficam disponíveis para a reflexão do leitor.

\subsection{Tempo de Programa}

É possível observar que a probabilidade de sucesso dos clientes aumenta na medida em que estes se mantêm no programa. O Gráfico 1 mostra que o cliente, ao permanecer no programa, tem maiores chances de superar a condição de pobreza, em todas as linhas delimitadoras deste estado. Essa probabilidade de sucesso chega a $44 \%$ para aqueles com cinco anos ou mais de programa para a linha de meio salário mínimo, indicando assim retornos maiores de renda em relação ao tempo de permanência no programa.

Um outro resultado derivado importante é a velocidade de saída da pobreza. Esta tem uma média anual entre $6 \%$ e $8 \%$ até o quinto ano de programa, o que caracteriza uma grande efetividade do programa em melhorar a renda dos clientes mais pobres. ${ }^{15}$

15 A título de comparação, Chowdhury et al. (2005) estimaram uma média anual de velocidade de saída da pobreza para clientes de microcrédito em Bangladesh da ordem de 3.5\% a 4\%. Embora a comparação não seja apropriada pela diferenciação conceitual da pobreza, ela ainda sugere uma eficácia absoluta elevada. 


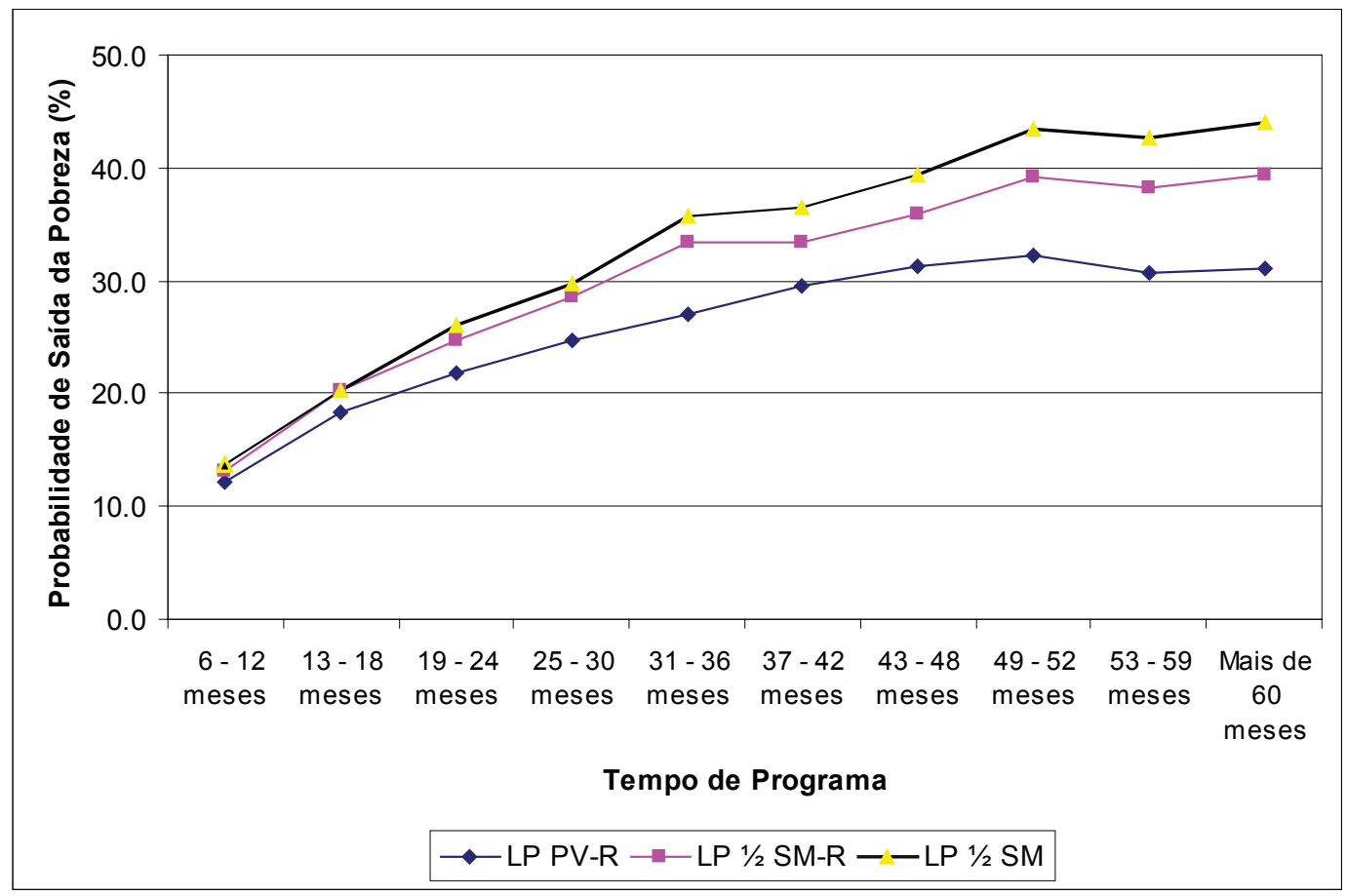

\section{Gráfico 1 - Probabilidade de Saída da Situação de Pobreza por Tempo de Programa}

Este padrão de eficácia elevado pode estar sendo induzido pela interação do apoio técnico do programa com o processo natural de learning-by-doing do nanoempresário. Ou seja, à medida que o cliente fica no programa, sua absorção das informações prestadas pelo programa, juntamente com sua prática empresarial, melhoram suas chances de aumento da renda. ${ }^{16}$ Deve-se ponderar, no entanto, que nossa amostra considerou apenas os clientes que permaneceram no programa, sendo possível que haja algum viés de dropout (KARLAN, 2001) de clientes menos eficientes que deixaram o programa. Em contrapartida, a inclusão de clientes que se encontram em situação de inadimplência ameniza este viés.

\subsection{Características do Indivíduo e da Família}

Quanto às características individuais, podemos destacar a influência positiva da educação na saída da condição de pobreza. Essa constatação indica que, mesmo en-

16 Vale ressaltar que, sem um grupo de controle para servir de contrafactural, não podemos atribuir ao programa os méritos desta velocidade de saída da pobreza. Ou seja, este padrão de fuga da condição de pobreza caracteriza o programa, mas o inverso não pode ser constatado com a base de dados disponível. 
tre os mais pobres, o capital humano é relativamente remunerado em concordância com o que acontece em setores formais mais capitalizados.

Com relação ao gênero, embora o homem tenha mostrado uma probabilidade maior de sucesso que as mulheres, esta última apresenta um grau de inadimplência menor. ${ }^{17} \mathrm{~A}$ conjugação destes resultados aponta para uma posição mais conservadora das mulheres, com uma preocupação comparativa de adimplência maior que a de retornos (ARMENDARIZ; MORDUCH, 2005).

Indivíduos que moram com parentes, em domicílios emprestados ou em outros arranjos, possuem uma probabilidade menor de sair da pobreza do que aqueles que possuem domicílio próprio, indicando que a presença de ativos particulares pode favorecer o crescimento. Entretanto, é interessante observar que aqueles que pagam aluguel têm uma probabilidade maior de sair da pobreza em relação aos com domicílio próprio, o que sinaliza que compromissos de pagamentos recorrentes podem ter um efeito de incentivo extra, e que a posse da propriedade parece ter mais influência no acesso ao crédito, como enfocado por De Soto (2000), do que no desenvolvimento do nanonegócio após seu recebimento.

Como esperado, verificamos que outras receitas familiares, ao entrar no programa, influenciam positivamente no sucesso dos nanoempresários. Este resultado, no entanto, deriva da participação desta variável na composição da renda per capita familiar inicial como vimos anteriormente, e apenas sinaliza que quanto mais próximo se está das linhas delimitadoras do estado de pobreza, mais fácil será cruzá-las.

\subsection{Características da Empresa}

Com certa surpresa, verificamos que o tempo de atividade do empreendimento não mostrou ter uma correlação importante com a probabilidade de sucesso. Isto pode sinalizar um viés de entrada no programa para empresas em dificuldades. Ou seja, as nanoempresas já existentes recorrem ao crédito em seus pontos de declínio, o que torna o tempo de mercado menos significante, principalmente se comparado ao tempo de programa. O que facilita um bom desempenho são as habilidades gerenciais preexistentes. Para os empreendedores que já possuíam certos controles administrativos satisfatórios ${ }^{18}$ nos seus nanonegócios antes da entrada no programa, a probabilidade de saída da pobreza foi aproximadamente 6 pontos porcentuais (p.p.) maior que aqueles sem nenhum controle.

17 A inadimplência feminina é aproximadamente $10 \%$ menor que a do homem, que fica em torno de $1 \%$ para contratos de até 90 dias.

18 Essa classificação é subjetiva, e preenchida no cadastro pelo assessor de crédito na visita prévia à concessão de crédito. 
Outra evidência importante foi que os nanonegócios com atividades ambulantes possuem uma menor probabilidade de prosperarem em relação àqueles com um ponto fixo. Esta evidência é também conciliadora com a ideia de retornos diferenciados para melhores colaterais produtivos.

A possibilidade de realizar vendas a prazo também parece ter uma influência positiva na probabilidade de sucesso em ultrapassar a linha da pobreza. ${ }^{19}$ Isto pode ser resultado de uma ação mais intensa de vendas por parte dos clientes somada a uma possível disponibilidade relativa maior de capital para financiar o prazo maior. Ressalta-se ainda que um dos objetivos da linha de capital de giro do microcrédito é exatamente financiar as vendas a prazo.

\subsection{Características do Empréstimo}

Como se esperava, o valor do empréstimo concedido no primeiro crédito se mostrou relevante e significante para a saída da pobreza. Esta variável foi segmentada por faixas de valores e o resultado indicou que a probabilidade de fuga da pobreza aumenta com o valor recebido, mas esta relação ocorre a taxas decrescentes. Para a linha de pobreza, LP PV-R, ocorre um ponto de maximização do retorno no limite de $\mathrm{R} \$ 700,00$. Esta evidência de retornos decrescentes, para o valor inicial do empréstimo, é importante para manter uma estratégia de compatibilidade entre o tamanho do empréstimo e o tamanho inicial do empreendimento.

Por outro lado, prazos maiores de pagamento mostraram ser negativamente correlacionados com a probabilidade de sucesso do nanoempreendedor. Estes resultados, em conjunto, sinalizam a eficácia da metodologia de empréstimos mais curtos e de valores iniciais modestos, por garantirem um acompanhamento mais próximo e com incentivos de renovações mais rápidos.

\subsection{Características Regionais}

Outro resultado interessante observado foi o efeito quadrático da probabilidade de saída da pobreza em relação à renda per capita municipal. Este resultado pode sinalizar que as facilidades de ascensão econômica dos mais pobres são maiores em municípios de médio porte, que têm, ao mesmo tempo, demanda potencial e oferta competitiva menos acirrada.

19 Embora isso só ocorra mais acentuadamente quando se tem capacidade de venda para prazos de três meses. 
De uma maneira geral, os resultados indicam que, mesmo entre os pobres, existe potencial para crescimento quando as oportunidades de crédito são consubstanciadas com dotações de capital inicial como de qualquer outro agente econômico. $\mathrm{Ou}$ seja, o capital humano e organizacional, colaterais produtivos, incentivos de crédito e oportunidades de mercado também são valorizados pelos nanocapitalistas.

\section{Considerações Finais}

A literatura econômica sempre foi pródiga em apontar "receituários" de desenvolvimento econômico dando demasiada ênfase a orientações de políticas como industrialização (Rostow) e tecnologia (Solow), por exemplo, sem que houvesse um detalhamento maior dos condicionantes adicionais que contribuiriam para a efetividade destas políticas. A "bola da vez" agora, pelo menos em relação a políticas de desenvolvimento de combate à pobreza, parecem ser, em parte, os incentivos às microfinanças, e mais uma vez observa-se na literatura uma preocupação muito grande em validar (ou não) esta política com análises de impacto, sem que se identifiquem também os condicionantes auxiliadores (ou impeditivos) de sucesso.

Neste trabalho, procuramos identificar um conjunto de fatores que contribuem para que programas de microcrédito possam realmente melhorar as condições de vida de seus clientes. O estudo de caso refere-se ao programa Crediamigo do Banco do Nordeste do Brasil, que é o maior programa de microcrédito orientado do Brasil e segundo maior da América Latina.

Primeiro encontramos uma alta eficácia do programa em aliviar as condições de pobreza dos seus clientes nanoempreendedores. Nos primeiros cinco anos de programa, uma média de $6 \%$ a $8 \%$ dos clientes ultrapassa a linha da pobreza anualmente. Esta velocidade de fuga, no entanto, é maior nos primeiros anos de programa e amortece principalmente a partir do quarto ano. Estimamos, portanto, que aproximadamente entre $30 \%$ e $40 \%$ dos clientes que entram no programa, com renda familiar delimitada por padrões de pobreza, deixam essa situação com até cinco anos de programa. Sendo esta estimativa controlada por vários fatores explicativos de sucesso, podemos inferir que a política de monitoramento porta-a-porta do programa Crediamigo é bastante eficaz.

Segundo, observamos que os padrões de remuneração de ativos (físicos ou capacitadores) dos mais pobres se assemelham a qualquer outro de um empresário do topo da pirâmide produtiva. Ou seja, maiores retornos são extraídos para aqueles nanoempresários mais dotados de capital humano (educação), de uma melhor estrutura organizacional e de colaterais produtivos (nanoempreendimentos com ponto fixo, 
por exemplo). Estas evidências corroboram a visão teórica do potencial empresarial dos mais pobres (DE SOTO, 2000), e do apelo normativo de que estes precisam de um "choque de mercado" (NÉRI, 2001) como condição fundamental para uma inserção social sustentável.

Terceiro, com relação às condições de empréstimos iniciais, constatamos que prazos menores com incentivos de renovações contínuas e ligeiramente crescentes produzem uma maior efetividade de alavancagem de renda dos clientes mais pobres. Ou seja, os créditos iniciais com prazos mais curtos e com valores modestos determinaram um retorno relativo maior que os empréstimos com prazos mais longos e de valores muito menores (ou muito maiores). Estas constatações demandam uma estratégia de monitoramento dos programas de microfinanciamentos que permite agilidade nas renovações (e/ou renegociações) de crédito, um acompanhamento regular dos clientes e um processo de seleção de novos clientes orientado por agentes de crédito com uma boa leitura das potencialidades e adaptações do nanoempreendimento e do mercado.

Finalmente, uma leitura geral dos resultados encontrados neste artigo sinaliza que é viável uma estratégia múltipla de parcerias com o setor público que favoreça o autossustento dos programas de microcrédito e dos seus clientes por meio de políticas educacionais, estruturais e de apoio técnico. Ou seja, é possível que o papel do Estado, enquanto agente de desenvolvimento sustentável, esteja mais voltado para a construção dos condicionantes básicos exigidos pelo mercado, do que para a influência direta neste, ou para uma assistência unilateral de fomento sem contrapartida mercadológica.

No entanto, para o fortalecimento destes argumentos são necessários estudos complementares que permitam incluir outros determinantes de saída da pobreza como fatores institucionais e culturais, e principalmente fatores de interações entre políticas sociais inclusivas e programas de microcrédito.

\section{Referências}

ALESINA, A.; RODRICK, D. Distributive policies and economic growth. Quarterly Journal of Economics, v.109 p. 465-90, 1994.

ARMENDARIZ, B. A.; MORDUCH, J. The economics of microfinance. Cambridge, MA: The MIT Press, 2005.

CHOWDHURY, M. J. A.; GHOSH, D.; WHIGHT, R. E. The impact of microcredit on poverty: Evidence from Bangladesh. Progress in Development Studies, v. 5 , n. 4,2005 . 
COPESTAKE, J.; DAWSON, P. ; FANNING, A.; MCKAY, A.; WRIGHT-REVOLLE$\mathrm{DO}, \mathrm{K}$. Monitoring diversity of poverty outreach and impact of microfinance: a comparison of methods using data from Peru. Development Policy Review, v. 23, n. 5, 2005.

DE SOTO, H. O mistério do capital. Rio de Janeiro: Record, 2000.

GOLDBERG, N. Measuring the impact of microfinance: taking stock of what we know. Washington, DC: Grameen Foundation USA, 2005. (Publication Series). Disponível em: <http://www.grameenfoundation.org > .

HULME, D.; MOSLEY, P. Finance against poverty. London: Routledge, 1996. v. 1 e 2 .

KARLAN, D. Microfinance impact assessments: the perils of using new members as a control group. Journal of Microfinance, v. 3, n. 2, 2001. Disponível em: < https:// marriottschool.byu.edu/esrreview/current/JMF_fall01.pdf\#page $=78>$.

KHANDKER, S. R. Micro-finance and poverty - Evidence using panel data from Bangladesh. Policy Research Working Paper 2945. Washington, DC: The World Bank, 2003.

LONG, J. S. Regression models for categorical and limited dependent variables. Thousand Oaks, Califórnia: SAGE Publications, 1997.

MANSO, C. A.; GORDIN, F. O.; SILVA, R. A. Uma análise comparativa sobre a evolução dos principais indicadores de bem-estar para o Brasil, Regiões e Estados pós-plano real. Fortaleza: Laboratório de Estudos da Pobreza - CAEN-UFC, 2008.

MORDUCH, J. Does microfinance really help the poor? New Evidence from Flagship Programs in Bangladesh, 1998. Mimeo.

NERI, M. C. Mapa de ativos: combate sustentável à pobreza. Rio de Janeiro: Fundação Getulio Vargas, IBRE, CPS, 2001.

PEROTTI, R. Income distribution, politics and growth. American Economic Review, v. 82, p. 311-16, 1992.

PERSSON, T.; TABELLINI, G. Is inequality harmful for growth? Theory and evidence. American Economic Review, v. 84 p. 600-21, 1994.

SCHRIEDER, G.; SHARMA, M. Impact of finance on poverty reduction and social capital formation: a review and synthesis of empirical evidence. Savings and Development, 23 p. 67-93, 1999.

SEBSTAD, J.; CHEN, G. Overview of studies of the impact of microenterprise credit. Washington D.C: Management Systems International, 1996.

SHARMA, M.; BUCHENRIEDER, G. Impact of microfinance on food security and poverty alleviation: a review and synthesis of empirical evidence. In: ZELLER, M.; MEYER, R. L. (Ed.). The triangle of microfinance: financial sustainability, outreach and impact. Baltimore MD: John Hopkins University Press, 2002. 
World Bank. Brazil Measuring Poverty Using Household Consumption, 2007. (Report No. 36358-BR). Disponível em < http://web.worldbank.org > . Acesso em 23/01/2008. 


\section{Apêndice A}

Tabela A.1 - Média das Variáveis Explicativas

\begin{tabular}{|c|c|c|c|}
\hline & LP PV-R & LP $1 / 2$ SM-R & LP $1 / 2 S M$ \\
\hline Renda Familiar Per capita Inicial (R\$ de Out.2006) & 83.77 & 112.81 & 118.16 \\
\hline Renda Familiar Per capita Final (R\$ de Out.2006) & 166.08 & 198.75 & 204.29 \\
\hline \multicolumn{4}{|l|}{ Tempo de Programa } \\
\hline $0-5$ meses & 0.1692 & 0.1648 & 0.1638 \\
\hline $6-12$ meses & 0.1710 & 0.1704 & 0.1695 \\
\hline $13-18$ meses & 0.1342 & 0.1337 & 0.1327 \\
\hline $19-24$ meses & 0.1006 & 0.1015 & 0.1007 \\
\hline $25-30$ meses & 0.0882 & 0.0886 & 0.0894 \\
\hline $31-36$ meses & 0.0645 & 0.0681 & 0.0684 \\
\hline $37-42$ meses & 0.0661 & 0.0661 & 0.0662 \\
\hline $43-48$ meses & 0.0493 & 0.0501 & 0.0507 \\
\hline $49-54$ meses & 0.0397 & 0.0424 & 0.0432 \\
\hline $55-60$ meses & 0.0286 & 0.0313 & 0.0320 \\
\hline Mais de 60 meses & 0.0887 & 0.0830 & 0.0834 \\
\hline \multicolumn{4}{|l|}{ Características Individuais } \\
\hline Idade (em anos) & 36.88 & 37.13 & 37.20 \\
\hline Masculino & 0.2979 & 0.3176 & 0.3199 \\
\hline Analfabeto & 0.0500 & 0.0438 & 0.0424 \\
\hline $1^{\circ}$ Grau Incompleto & 0.5934 & 0.5793 & 0.5763 \\
\hline $1^{\circ} \mathrm{Grau}$ Completo & 0.1241 & 0.1315 & 0.1328 \\
\hline $2^{\circ}$ Grau Incompleto & 0.0479 & 0.0491 & 0.0488 \\
\hline $2^{\circ}$ Grau Completo & 0.1676 & 0.1769 & 0.1798 \\
\hline Superior Incompleto & 0.0073 & 0.0087 & 0.0089 \\
\hline Superior Completo & 0.0098 & 0.0108 & 0.0110 \\
\hline Domicílio Próprio & 0.7508 & 0.7594 & 0.7618 \\
\hline Domicílio Alugado & 0.0870 & 0.0882 & 0.0886 \\
\hline Domicílio Parentes & 0.0624 & 0.0532 & 0.0519 \\
\hline Domicílio Outros & 0.0697 & 0.0715 & 0.0701 \\
\hline Domicílio Emprestado & 0.0302 & 0.0276 & 0.0276 \\
\hline \multicolumn{4}{|l|}{ Características do Negócio } \\
\hline Tempo de Atividade (em anos) & 6.09 & 6.02 & 6.06 \\
\hline Contr. Adm. Inexistente & 0.1869 & 0.1723 & 0.1686 \\
\hline Contr. Adm. Precário & 0.5047 & 0.4889 & 0.4892 \\
\hline Contr. Adm. Bom & 0.0754 & 0.0784 & 0.0780 \\
\hline Contr. Adm. Satisfatório & 0.2330 & 0.2603 & 0.2642 \\
\hline Negócio Fixo & 0.5633 & 0.5966 & 0.5996 \\
\hline Negócio Ambulante & 0.4367 & 0.4034 & 0.4004 \\
\hline Vendas à vista & 0.3999 & 0.3990 & 0.3972 \\
\hline Vendas_prazo1 & 0.5129 & 0.5092 & 0.5107 \\
\hline Vendas_prazo2 & 0.0819 & 0.0855 & 0.0856 \\
\hline Vendas_prazo3 & 0.0052 & 0.0063 & 0.0065 \\
\hline Comércio & 0.9145 & 0.9186 & 0.9179 \\
\hline Indústria & 0.0361 & 0.0319 & 0.0321 \\
\hline Serviço & 0.0495 & 0.0495 & 0.0501 \\
\hline
\end{tabular}


Tabela A.1 - Média das Variáveis Explicativas (continuação)

\begin{tabular}{|c|c|c|c|}
\hline & LP PV-R & LP $1 / 2$ SM-R & LP $1 / 2$ SM \\
\hline \multicolumn{4}{|l|}{ Características do Empréstimo } \\
\hline Valor R\$ - 200 & 0.1194 & 0.0752 & 0.0710 \\
\hline Valor $\mathrm{R} \$ 201$ - 300 & 0.2935 & 0.2304 & 0.2211 \\
\hline Valor $\mathrm{R} \$ 301$ - 400 & 0.3005 & 0.2916 & 0.2887 \\
\hline Valor $\mathrm{R} \$ 401$ - 500 & 0.1752 & 0.2153 & 0.2180 \\
\hline Valor $\mathrm{R} \$ 501$ - 600 & 0.0862 & 0.1349 & 0.1410 \\
\hline Valor $\mathrm{R} \$ 601$ - 700 & 0.0137 & 0.0264 & 0.0295 \\
\hline Valor $\mathrm{R} \$ 701$ - 800 & 0.0064 & 0.0131 & 0.0151 \\
\hline Valor $\mathrm{R} \$ 801$ - & 0.0051 & 0.0131 & 0.0155 \\
\hline Part. Empréstimo do Grupo & 19.98 & 20.84 & 20.91 \\
\hline Prestações 3 meses & 0.4686 & 0.4663 & 0.4667 \\
\hline Prestações 4 meses & 0.4057 & 0.4165 & 0.4145 \\
\hline Prestações 5 meses & 0.0332 & 0.0306 & 0.0319 \\
\hline Prestações 6 meses & 0.0798 & 0.0741 & 0.0744 \\
\hline Prestações Mais de 6 meses & 0.0127 & 0.0125 & 0.0125 \\
\hline \multicolumn{4}{|l|}{ Controle Temporal } \\
\hline D1998 & 0.0112 & 0.0074 & 0.0075 \\
\hline D1999 & 0.0253 & 0.0179 & 0.0171 \\
\hline D2000 & 0.0195 & 0.0219 & 0.0222 \\
\hline D2001 & 0.0425 & 0.0472 & 0.0480 \\
\hline D2002 & 0.0755 & 0.0803 & 0.0819 \\
\hline D2003 & 0.1215 & 0.1227 & 0.1231 \\
\hline D2004 & 0.1637 & 0.1672 & 0.1684 \\
\hline D2005 & 0.2596 & 0.2602 & 0.2580 \\
\hline D2006 & 0.2810 & 0.2752 & 0.2737 \\
\hline \multicolumn{4}{|l|}{ Características Regionais } \\
\hline Ceará & 0.4062 & 0.3670 & 0.3809 \\
\hline Alagoas & 0.0408 & 0.0480 & 0.0488 \\
\hline Maranhão & 0.0794 & 0.0950 & 0.0963 \\
\hline Rio Grande do Norte & 0.0282 & 0.0345 & 0.0364 \\
\hline Espírito Santo & 0.0002 & 0.0001 & 0.0004 \\
\hline Piauí & 0.0411 & 0.0548 & 0.0566 \\
\hline Pernambuco & 0.1354 & 0.1335 & 0.1171 \\
\hline Bahia & 0.0788 & 0.0897 & 0.0858 \\
\hline Minas Gerais & 0.0394 & 0.0301 & 0.0361 \\
\hline Sergipe & 0.0593 & 0.0544 & 0.0517 \\
\hline Paraíba & 0.0913 & 0.0928 & 0.0898 \\
\hline Renda Per Capita Municipal (R\$ 100) & 1.1525 & 1.1744 & 1.1815 \\
\hline
\end{tabular}


Tabela A.2 - Modelo Logit de Probabilidade de Sucesso em Ultrapassar a Linha da Pobreza

\begin{tabular}{|c|c|c|c|c|c|c|}
\hline & \multicolumn{2}{|c|}{$\begin{array}{c}\text { LP PV-R } \\
(\mathrm{R} \$ 117,04)^{1}\end{array}$} & \multicolumn{2}{|c|}{$\begin{array}{l}\text { LP 1/2 SM-R } \\
(\mathrm{R} \$ 162,77)^{1}\end{array}$} & \multicolumn{2}{|c|}{$\begin{array}{c}\text { LP } 1 / 2 \text { SM } \\
(\mathrm{R} \$ 175,00)\end{array}$} \\
\hline & $\begin{array}{c}\text { Coeficiente } \\
\text { Logit }\end{array}$ & $\begin{array}{c}\text { Efeito } \\
\text { Marginal }\end{array}$ & $\begin{array}{c}\text { Coeficiente } \\
\text { Logit }\end{array}$ & $\begin{array}{c}\text { Efeito } \\
\text { Marginal }\end{array}$ & $\begin{array}{c}\text { Coeficiente } \\
\text { Logit }\end{array}$ & $\begin{array}{c}\text { Efeito } \\
\text { Marginal }\end{array}$ \\
\hline \multicolumn{7}{|l|}{ Tempo de Programa } \\
\hline $6-12$ meses & $\begin{array}{c}0.5378^{\star *} \\
(9.85)\end{array}$ & 0.1209 & $\begin{array}{c}0.5330^{\star *} \\
(13.06)\end{array}$ & 0.1313 & $\begin{array}{c}0.5499^{\star *} \\
(13.85)\end{array}$ & 0.1363 \\
\hline $13-18$ meses & $\begin{array}{l}0.8587^{\star *} \\
(10.08)\end{array}$ & 0.1834 & $\begin{array}{l}0.8472^{\star *} \\
(13.67)\end{array}$ & 0.2035 & $\begin{array}{l}0.8339^{* *} \\
(13.84)\end{array}$ & 0.2031 \\
\hline $19-24$ meses & $\begin{array}{c}1.0751^{* \star} \\
(11.56)\end{array}$ & 0.2188 & $\begin{array}{l}1.0611^{\star *} \\
(15.84)\end{array}$ & 0.2480 & $\begin{array}{l}1.0967^{\star *} \\
(16.88)\end{array}$ & 0.2598 \\
\hline $25-30$ meses & $\begin{array}{c}1.2609^{\star *} \\
(9.89)\end{array}$ & 0.2464 & $\begin{array}{l}1.2622^{* *} \\
(14.20)\end{array}$ & 0.2865 & $\begin{array}{l}1.2890^{* *} \\
(15.05)\end{array}$ & 0.2979 \\
\hline $31-36$ meses & $\begin{array}{c}1.4653^{\star \star} \\
(10.65)\end{array}$ & 0.2707 & $\begin{array}{l}1.5480^{\star *} \\
(16.35)\end{array}$ & 0.3338 & $\begin{array}{c}1.6345^{\star \star} \\
(17.94)\end{array}$ & 0.3569 \\
\hline $37-42$ meses & $\begin{array}{c}1.6735^{\star *} \\
(9.44)\end{array}$ & 0.2959 & $\begin{array}{l}1.5562^{\star *} \\
(13.05)\end{array}$ & 0.3348 & $\begin{array}{l}1.6884^{* *} \\
(14.87)\end{array}$ & 0.3651 \\
\hline $43-48$ meses & $\begin{array}{l}1.8892^{* *} \\
(9.99)\end{array}$ & 0.3135 & $\begin{array}{l}1.7324^{\star *} \\
(13.75)\end{array}$ & 0.3583 & $\begin{array}{l}1.9012^{* *} \\
(15.90)\end{array}$ & 0.3930 \\
\hline $49-54$ meses & $\begin{array}{c}2.0265^{* *} \\
(8.09)\end{array}$ & 0.3225 & $\begin{array}{c}2.0148^{\star *} \\
(12.77)\end{array}$ & 0.3924 & $\begin{array}{c}2.2621^{* *} \\
(15.26)\end{array}$ & 0.4341 \\
\hline $55-60$ meses & $\begin{array}{l}1.8737^{* *} \\
(7.04)\end{array}$ & 0.3061 & $\begin{array}{l}1.9490^{* *} \\
(11.61)\end{array}$ & 0.3817 & $\begin{array}{l}2.2252^{* *} \\
(14.13)\end{array}$ & 0.4264 \\
\hline Mais de 60 meses & $\begin{array}{c}1.7539^{* *} \\
(4.97)\end{array}$ & 0.3104 & $\begin{array}{l}1.9393^{* *} \\
(9.18)\end{array}$ & 0.3938 & $\begin{array}{l}2.2069^{* *} \\
(11.27)\end{array}$ & 0.4406 \\
\hline \multicolumn{7}{|c|}{ Características Individuais } \\
\hline Idade & $\begin{array}{l}0.0236^{* *} \\
(2.82)\end{array}$ & 0.0057 & $\begin{array}{l}0.0000 \\
(0.00)\end{array}$ & 0.0000 & $\begin{array}{c}-0.0031 \\
(0.59)\end{array}$ & -0.0008 \\
\hline Idade2 & $\begin{array}{c}-0.0004^{\star *} \\
(3.55)\end{array}$ & -0.0001 & $\begin{array}{c}-0.0001 \\
(1.51)\end{array}$ & 0.0000 & $\begin{array}{c}-0.0001 \\
(1.13)\end{array}$ & 0.0000 \\
\hline Masculino & $\begin{array}{c}0.0815^{\star} \\
(2.30)\end{array}$ & 0.0192 & $\begin{array}{l}0.1316^{\star *} \\
(5.64)\end{array}$ & 0.0329 & $\begin{array}{l}0.1355^{\star \star} \\
(6.12)\end{array}$ & 0.0338 \\
\hline $1^{\circ}$ Grau Incompleto & $\begin{array}{c}0.3429^{* \star} \\
(4.90)\end{array}$ & 0.0816 & $\begin{array}{c}0.2693^{* *} \\
(5.07)\end{array}$ & 0.0672 & $\begin{array}{c}0.2815^{\star *} \\
(5.54)\end{array}$ & 0.0701 \\
\hline $1^{\circ}$ Grau Completo & $\begin{array}{c}0.4893^{\star *} \\
(6.05)\end{array}$ & 0.1099 & $\begin{array}{c}0.4575^{\star \star} \\
(7.74)\end{array}$ & 0.1129 & $\begin{array}{c}0.4457^{\star *} \\
(7.90)\end{array}$ & 0.1108 \\
\hline $2^{\circ}$ Grau Incompleto & $\begin{array}{c}0.4741^{\star *} \\
(4.87)\end{array}$ & 0.1055 & $\begin{array}{c}0.4475^{\star \star} \\
(6.42)\end{array}$ & 0.1101 & $\begin{array}{c}0.4275^{\star \star} \\
(6.42)\end{array}$ & 0.1061 \\
\hline $2^{\circ}$ Grau Completo & $\begin{array}{l}0.5398^{* *} \\
(6.75)\end{array}$ & 0.1213 & $\begin{array}{c}0.4239^{\star *} \\
(7.19)\end{array}$ & 0.1050 & $\begin{array}{c}0.4478^{\star \star} \\
(7.95)\end{array}$ & 0.1114 \\
\hline Superior Incompleto & $\begin{array}{c}0.4503^{*} \\
(2.53)\end{array}$ & 0.1000 & $\begin{array}{c}0.4390^{\star *} \\
(3.64)\end{array}$ & 0.1079 & $\begin{array}{c}0.4115^{\star \star} \\
(3.62)\end{array}$ & 0.1021 \\
\hline Superior Completo & $\begin{array}{c}0.8467^{\star \star} \\
(4.93)\end{array}$ & 0.1741 & $\begin{array}{c}0.3242^{* *} \\
(2.88)\end{array}$ & 0.0803 & $\begin{array}{c}0.5013^{\star \star} \\
(4.69)\end{array}$ & 0.1239 \\
\hline Domicílio Alugado & $\begin{array}{c}0.0066 \\
(0.12)\end{array}$ & 0.0016 & $\begin{array}{c}0.0682+ \\
(1.84)\end{array}$ & 0.0170 & $\begin{array}{c}0.0816^{*} \\
(2.33)\end{array}$ & 0.0204 \\
\hline Domicílio Parentes & $\begin{array}{c}-0.3859^{\star *} \\
(5.99)\end{array}$ & -0.0941 & $\begin{array}{c}-0.5441^{\star *} \\
(11.07)\end{array}$ & -0.1335 & $\begin{array}{c}-0.5557^{\star *} \\
(11.57)\end{array}$ & -0.1344 \\
\hline Domicílio Outros & $\begin{array}{c}-0.0899 \\
(1.59)\end{array}$ & -0.0215 & $\begin{array}{c}-0.1681^{\star *} \\
(4.22)\end{array}$ & -0.0420 & $\begin{array}{c}-0.1675^{\star \star} \\
(4.37)\end{array}$ & -0.0416 \\
\hline Domicílio Emprestado & $\begin{array}{c}-0.1089 \\
(1.21)\end{array}$ & -0.0261 & $\begin{array}{c}-0.0699 \\
(1.11)\end{array}$ & -0.0175 & $\begin{array}{c}-0.0277 \\
(0.46)\end{array}$ & -0.0069 \\
\hline $\begin{array}{l}\text { Outras Receitas } \\
\text { Familiares }\end{array}$ & $\begin{array}{c}0.0016^{\star *} \\
(13.02)\end{array}$ & 0.0004 & $\begin{array}{c}0.0014^{\star *} \\
(19.89)\end{array}$ & 0.0003 & $\begin{array}{l}0.0015^{\star \star} \\
(22.44)\end{array}$ & 0.0004 \\
\hline
\end{tabular}


Tabela A.2 - Modelo Logit de Probabilidade de Sucesso em Ultrapassar a Linha da Pobreza (continuação)

\begin{tabular}{|c|c|c|c|c|c|c|}
\hline & \multicolumn{2}{|c|}{$\begin{array}{c}\text { LP PV-R } \\
(\mathrm{R} \$ 117,04)^{1}\end{array}$} & \multicolumn{2}{|c|}{$\begin{array}{c}\text { LP } 1 / 2 \text { SM-R } \\
(\mathrm{R} \$ 162,77)^{1}\end{array}$} & \multicolumn{2}{|c|}{$\begin{array}{c}\text { LP } 1 / 2 \text { SM } \\
(\mathrm{R} \$ 175,00)\end{array}$} \\
\hline & $\begin{array}{c}\text { Coeficiente } \\
\text { Logit }\end{array}$ & $\begin{array}{c}\text { Efeito } \\
\text { Marginal }\end{array}$ & $\begin{array}{c}\text { Coeficiente } \\
\text { Logit }\end{array}$ & $\begin{array}{c}\text { Efeito } \\
\text { Marginal }\end{array}$ & $\begin{array}{c}\text { Coeficiente } \\
\text { Logit }\end{array}$ & $\begin{array}{c}\text { Efeito } \\
\text { Marginal }\end{array}$ \\
\hline \multicolumn{7}{|l|}{ Características do Negócio } \\
\hline Tempo de Atividade & $\begin{array}{l}0.0001 \\
(0.02)\end{array}$ & 0.0000 & $\begin{array}{l}0.0028 \\
(1.61)\end{array}$ & 0.0007 & $\begin{array}{c}0.0034+ \\
(1.91)\end{array}$ & 0.0008 \\
\hline Tempo de Atividade ${ }^{2}$ & $\begin{array}{l}0.0000 \\
(1.31)\end{array}$ & 0.0000 & $\begin{array}{c}-0.0000 \\
(0.29)\end{array}$ & 0.0000 & $\begin{array}{c}-0.0000 \\
(0.38)\end{array}$ & 0.0000 \\
\hline Contr. Adm. Precário & $\begin{array}{l}0.0528 \\
(1.28)\end{array}$ & 0.0125 & $\begin{array}{l}0.0341 \\
(1.16)\end{array}$ & 0.0085 & $\begin{array}{l}0.0291 \\
(1.03)\end{array}$ & 0.0073 \\
\hline Contr. Adm. Bom & $\begin{array}{c}0.1569^{*} \\
(2.35)\end{array}$ & 0.0366 & $\begin{array}{c}0.1231^{\star *} \\
(2.76)\end{array}$ & 0.0307 & $\begin{array}{c}0.0821+ \\
(1.93)\end{array}$ & 0.0205 \\
\hline Contr. Adm. Satisfatório & $0.2436^{* *}$ & 0.0567 & $0.2395^{\star *}$ & 0.0597 & $0.2372^{* *}$ & 0.0592 \\
\hline Negócio Ambulante & $\begin{array}{c}-0.1441^{\star \star} \\
(4.46)\end{array}$ & -0.0342 & $\begin{array}{c}-0.1412^{\star *} \\
(6.32)\end{array}$ & -0.0353 & $\begin{array}{c}(1.53) \\
-0.1528^{\star \star} \\
(7.17)\end{array}$ & -0.0381 \\
\hline Vendas_prazo1 & $\begin{array}{c}0.0565 \\
(1.56)\end{array}$ & 0.0134 & $\begin{array}{c}0.0030 \\
(0.12)\end{array}$ & 0.0007 & $\begin{array}{l}0.0023 \\
(0.10)\end{array}$ & 0.0006 \\
\hline Vendas_prazo2 & $\begin{array}{l}0.0599 \\
(1.00)\end{array}$ & 0.0141 & $\begin{array}{c}0.0249 \\
(0.61)\end{array}$ & 0.0062 & $\begin{array}{l}0.0543 \\
(1.39)\end{array}$ & 0.0136 \\
\hline Vendas_prazo3 & $\begin{array}{c}0.4527^{*} \\
(2.13)\end{array}$ & 0.1004 & $\begin{array}{c}0.3864^{* *} \\
(3.03)\end{array}$ & 0.0953 & $\begin{array}{c}0.2110+ \\
(1.74)\end{array}$ & 0.0527 \\
\hline Indústria & $\begin{array}{c}-0.2309^{* *} \\
(2.82)\end{array}$ & -0.0558 & $\begin{array}{c}-0.1260^{*} \\
(2.14)\end{array}$ & -0.0315 & $\begin{array}{c}-0.1092+ \\
(1.95)\end{array}$ & -0.0272 \\
\hline Serviço & $\begin{array}{c}-0.0462 \\
(0.63)\end{array}$ & -0.0110 & $\begin{array}{c}-0.0928+ \\
(1.87)\end{array}$ & -0.0232 & $\begin{array}{c}-0.0964^{*} \\
(2.06)\end{array}$ & -0.0240 \\
\hline \multicolumn{7}{|l|}{ Características do Empréstimo } \\
\hline Valor $\mathrm{R} \$ 200$ - 300 & $\begin{array}{c}0.4692^{\star *} \\
(8.15)\end{array}$ & 0.1081 & $\begin{array}{c}0.4453^{* *} \\
(8.81)\end{array}$ & 0.1104 & $\begin{array}{c}0.4809^{* *} \\
(9.56)\end{array}$ & 0.1196 \\
\hline Valor $\mathrm{R} \$ 301$ - 400 & $\begin{array}{c}0.8777^{\star \star} \\
(14.79)\end{array}$ & 0.1961 & $\begin{array}{c}0.8147^{* *} \\
(16.18)\end{array}$ & 0.1993 & $\begin{array}{c}0.8694^{* \star} \\
(17.42)\end{array}$ & 0.2135 \\
\hline Valor $\mathrm{R} \$ 401$ - 500 & $\begin{array}{c}1.1009^{\star *} \\
(16.78)\end{array}$ & 0.2302 & $\begin{array}{c}1.0935^{\star *} \\
(20.72)\end{array}$ & 0.2603 & $\begin{array}{l}1.1273^{\star \star} \\
(21.74)\end{array}$ & 0.2711 \\
\hline Valor $\mathrm{R} \$ 501$ - 600 & $\begin{array}{c}1.2267^{\star *} \\
(15.92)\end{array}$ & 0.2411 & $\begin{array}{c}1.2945^{\star \star} \\
(23.03)\end{array}$ & 0.2966 & $\begin{array}{l}1.3556^{\star *} \\
(24.71)\end{array}$ & 0.3149 \\
\hline Valor $\mathrm{R} \$ 601$ - 700 & $\begin{array}{c}1.6052^{* *} \\
(9.59)\end{array}$ & 0.2766 & $\begin{array}{c}1.3893^{\star *} \\
(16.26)\end{array}$ & 0.3024 & $\begin{array}{c}1.4473^{\star \star} \\
(18.34)\end{array}$ & 0.3208 \\
\hline Valor $\mathrm{R} \$ 701$ - 800 & $\begin{array}{c}1.2912^{\star *} \\
(5.43)\end{array}$ & 0.2393 & $\begin{array}{l}1.5730^{\star *} \\
(13.74)\end{array}$ & 0.3288 & $\begin{array}{c}1.6147^{\star \star} \\
(15.67)\end{array}$ & 0.3454 \\
\hline Valor $\mathrm{R} \$$ Mais de 800 & $\begin{array}{c}1.0304^{* *} \\
(4.27)\end{array}$ & 0.2031 & $\begin{array}{c}1.6765^{\star *} \\
(14.82)\end{array}$ & 0.3433 & $\begin{array}{l}1.7477^{\star *} \\
(17.47)\end{array}$ & 0.3646 \\
\hline Part. Empréstimo do Grupo & $\begin{array}{c}-0.0071^{\star *} \\
(3.15)\end{array}$ & -0.0016 & $\begin{array}{c}-0.0031^{*} \\
(2.03)\end{array}$ & -0.0008 & $\begin{array}{c}-0.0042^{\star *} \\
(2.96)\end{array}$ & -0.0011 \\
\hline Prestações 4 meses & $\begin{array}{c}-0.0948^{* *} \\
(2.63)\end{array}$ & -0.0225 & $\begin{array}{c}-0.1601^{* *} \\
(6.52)\end{array}$ & -0.0400 & $\begin{array}{c}-0.1674^{* *} \\
(7.15)\end{array}$ & -0.0417 \\
\hline Prestações 5 meses & $\begin{array}{c}-0.6151^{* *} \\
(7.07)\end{array}$ & -0.1514 & $\begin{array}{c}-0.4955^{* *} \\
(7.79)\end{array}$ & -0.1218 & $\begin{array}{c}-0.4659^{* *} \\
(7.82)\end{array}$ & -0.1134 \\
\hline Prestações 6 meses & $\begin{array}{c}-0.0671 \\
(0.82)\end{array}$ & -0.0160 & $\begin{array}{l}-0.0582 \\
(1.14)\end{array}$ & -0.0145 & $\begin{array}{c}-0.0477 \\
(0.99)\end{array}$ & -0.0119 \\
\hline Prestações Mais de 6 meses & $\begin{array}{c}-0.2607+ \\
(1.74)\end{array}$ & -0.0633 & $\begin{array}{c}-0.5138^{\star *} \\
(5.38)\end{array}$ & -0.1260 & $\begin{array}{c}-0.5382^{\star *} \\
(5.93)\end{array}$ & -0.1299 \\
\hline
\end{tabular}


Tabela A.2 - Modelo Logit de Probabilidade de Sucesso em Ultrapassar a Linha da Pobreza (continuação)

\begin{tabular}{|c|c|c|c|c|c|c|}
\hline & \multicolumn{2}{|c|}{$\begin{array}{c}\text { LP PV-R } \\
(\mathrm{R} \$ 117,04)^{1}\end{array}$} & \multicolumn{2}{|c|}{$\begin{array}{l}\text { LP 1/2 SM-R } \\
(\mathrm{R} \$ 162,77)^{1}\end{array}$} & \multicolumn{2}{|c|}{$\begin{array}{c}\text { LP 1/2 SM } \\
(\mathrm{R} \$ 175,00)\end{array}$} \\
\hline & $\begin{array}{l}\text { Coeficiente } \\
\text { Logit }\end{array}$ & $\begin{array}{l}\text { Efeito } \\
\text { Marginal }\end{array}$ & $\begin{array}{l}\text { Coeficiente } \\
\text { Logit }\end{array}$ & $\begin{array}{c}\text { Efeito } \\
\text { Marginal }\end{array}$ & $\begin{array}{c}\text { Coeficiente } \\
\text { Logit }\end{array}$ & $\begin{array}{l}\text { Efeito } \\
\text { Marginal }\end{array}$ \\
\hline \multicolumn{7}{|l|}{ Características Regionais } \\
\hline $\begin{array}{l}\text { Renda Per Capita } \\
\text { Municipal(R\$ 100) }\end{array}$ & $\begin{array}{c}0.1973+ \\
(1.92)\end{array}$ & 0.0479 & $\begin{array}{c}0.3717^{\star *} \\
(5.46)\end{array}$ & 0.0914 & $\begin{array}{l}0.3047^{\star *} \\
(4.69)\end{array}$ & 0.0745 \\
\hline $\begin{array}{l}\text { Renda Per Capita Municipal } \\
\text { (R\$ 100) }\end{array}$ & $\begin{array}{l}0.0087 \\
(0.31)\end{array}$ & 0.0021 & $\begin{array}{c}-0.0437^{\star} \\
(2.38)\end{array}$ & -0.0109 & $\begin{array}{c}-0.0234 \\
(1.34)\end{array}$ & -0.0058 \\
\hline Efeitos Fixos (Estados) & SIM & & SIM & & SIM & \\
\hline $\begin{array}{l}\text { Efeitos Fixos } \\
\text { (Ano de entrada no } \\
\text { programa) }\end{array}$ & SIM & & SIM & & SIM & \\
\hline $\mathrm{N}$ & 24506 & & 49953 & & 55331 & \\
\hline
\end{tabular}

Obs: Estatística t-White robusto entre parênteses.

Notas: + Significante a $10 \% ;{ }^{*}$ Significante a $5 \% ;{ }^{* *}$ Significant a $1 \%$.

Categorias Base: Tempo de programa inferior a seis meses, sexo feminino, analfabeto, Domicílio próprio, Controle administrativo inexistente, Negócio fixo, Apenas vendas à vista, Setor agrícola, Empréstimo inferior a R \$200,00 (out. 2006), Pagamento de prestações em três meses ou menos, Entrada no Programa anterior a 1999, Estado do Ceará.

1 Média da linha de pobreza entre os Estados. 